\title{
La Arquitectura Escolar: Estudio de Percepciones
}

\author{
School Architecture: Perceptions Study
}

\section{Arquitetura da Escola: Estudio de Percepções}

\author{
Alexandre Camacho Prats * \\ Conselleria d'Educació i Universitat, Govern de les Illes Balears
}

\begin{abstract}
Presentamos una reciente investigación sobre la arquitectura escolar en España. Tras una revisión histórica y académica, entrevistamos a catorce informantes expertos (cuatro inspectores, cuatro arquitectos, tres responsables de la Administración y tres directores de escuela/instituto públicos) para saber sus percepciones sobre cómo se hacen las escuelas y qué papel juega la pedagogía antes de que se construyan. Los entrevistados resaltaron que en demasiadas ocasiones las exigencias políticas y las limitaciones económicas y temporales tienen más peso que los requerimientos de los usuarios. Además, sugirieron que su criterio debería tenerse en cuenta. Consecuentemente, proponemos la creación de una junta permanente de expertos asesores en materia de arquitectura escolar para con la Administración, que podría mejorar el diseño y construcción flexibles de escuelas e institutos en beneficio de todos.
\end{abstract}

Descriptores: Arquitectura, Administración de la educación, Enseñanza pública, Inspección escolar, Ciencias de la educación y ambiente educacional.

We show a recent research on school architecture in Spain. After a historical and academic review, we interviewed fourteen expert informants (four inspectors, four architects, three Government managers and three state school principals) to know their perceptions of how schools are made and what role pedagogy plays before centers are built. Respondents stressed that too often political demands and economic and temporal constraints outweigh the requirements of users. In addition, they suggested that their judgment should be taken into account. Consequently, we propose the creation of a permanent advisory committee on school architecture towards the Administration, to improve the flexible design and construction of schools and high schools for the general benefit.

Keywords: Architecture, Educational administration, Public education, School supervision, Educational sciences and environment.

Apresentamos uma pesquisa recente sobre a arquitetura escolar em Espanha. Depois de uma análise histórica e acadêmica, foram entrevistados catorze especialistas (quatro inspetores, quatro arquitetos, três funcionários da administração e três diretores de escolas públicas) para saber as suas posições sobre o funcionamento das escolas e sobre o papel do modelo pedagógico antes da sua construção. Os entrevistados salientaram que muitas vezes as exigências políticas, as restrições económicas e temporais são mais determinantes do que as necessidades dos utilizadores. Além disso sugerem que os critérios devem ser tidos em conta. Consequentemente, propomos a criação de um conselho permanente de consultores especializados para a administração da arquitetura escolar que poderia melhorar a conceção e construção das escolas e faculdades para o benefício de todos.

Palavras-chave: Arquitetura, Gestão da educação, Educação pública, Inspeção escola, Educação ciência e ambiente educacional.

*Contacto: alexcprats@hotmail.com

ISSN: 2254-3139

www.rinace.net/riejs/

revistas.uam.es/riejs
Recibido: $\quad 21$ de diciembre 2016

$1^{\text {a }}$ Evaluación: 18 de enero 2017

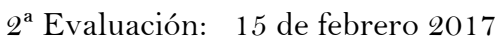

Aceptado: $\quad 28$ de febrero 2017 
El espacio, el ambiente, es el tercer maestro del niño o niña. (Loris Malaguzzi, en Hoyuelos, 2004, p. 60)

Algo más hay que hacer, por lo tanto, que construir escuelas. Hay que defenderlas, infundirles calor y vida. Ta sé que la tarea es gigantesca. Se trata nada menos que de construir una nación. (Bello, 2007, p. 9)

A mi me basta entrar en un local para saber si al pueblo le interesa la instrucción de sus hijos, si los quiere y si se respeta y estima al maestro. (Bello, 1926, p. 10)

\section{Introducción}

La influencia de la educación que recibimos las personas, especialmente en las etapas escolares, es de una relevancia incuestionable. Numerosos estudios, desde los clásicos (Delors, 1996; Faure, 1972) hasta los más recientes (MECD, 2016; OCDE, 2016) resaltan los beneficios de un adecuado aprovechamiento de la escolarización, tanto a nivel social, como cultural y económico. Los gobiernos tratan de invertir cantidades cada vez mayores para sufragar la enseñanza del mejor modo posible, a tenor de que la escuela, fundamentalmente la pública, es la institución por excelencia promotora de justicia social y valores básicos, a la vez que eje crucial en la vida de millones de personas.

En este sentido, hay muchos factores que pueden condicionar el devenir de la educación de los individuos, tales como el entorno familiar, las amistades, la calidad de los métodos didácticos recibidos y la implicación del profesorado, el liderazgo directivo, la supervisión de la enseñanza, el currículo, etc. Sin embargo, el espacio en el que se desarrolla la actividad escolar (que, en general, alberga muchos de los factores anteriormente citados) y en cuyo seno destinamos miles de horas durante nuestras vidas, es también importante. Los edificios escolares resultan ser el continente de unos contenidos que, trabajados pertinentemente, pueden contribuir a que nuestra instrucción y formación sea más grata. Además, el espacio escolar (con sus luces y sus sombras) condiciona la acción educativa, por lo que esta investigación que aquí se presenta ha pretendido indagar sobre la cuestión. No en vano, Hoyuelos (2004) nos recuerda que el citado Malaguzzi, reconocido pedagogo italiano de mediados del siglo xx, ya sostenía que los niños tienen tres maestros: el primero, sus compañeros; el segundo, los adultos que le rodean (profesorado, padres, familia, vecinos, etc.) y el tercero, el entorno construido (casa, escuela, barrio, ciudad). Veamos, pues, qué se puede mejorar de ese "tercer maestro" escolar que todo niño y niña tiene.

\section{Fundamentación teórica}

\subsection{Un repaso al recorrido histórico}

\subsubsection{Los inicios de la Edad Contemporánea}

En el año 1792, en plena Revolución Francesa, el Conde de Cabarrús redactó una de sus cartas dedicada a la educación, denominada "Carta sobre los obstáculos de opinión y el medio de removerles con la circulación de las luces", y un sistema general de educación, en la que sostiene cómo ha de ser la enseñanza que debe darse a la generación naciente, que debe ofrecer "todos los conocimientos elementales que todo hombre puede exigir de la sociedad" (Cabarrús, 1973, p. 121). En sus escritos plantea un "nuevo sistema general 
de enseñanza" mediante la escuela común a todos hasta los 10 años de edad. A esta escuela la llega a denominar como "templo patriótico" en el que todos los niños y niñas descubran las bases educativas que les permitan desarrollarse:

Véase cuán sencillos son los conocimientos elementales que todo hombre puede exigir de la sociedad, que ésta debe a todos sin distinción, y sin los cuales quebranta la esencia de su pacto. Leer, escribir, contar, medir; deje vuestra merced obrar después a la actividad [...]. En una palabra, amigo mío, la sociedad debe, en primer lugar, a sus conciudadanos la más libre comunicación de sus luces, y en segundo, los auxilios que deben prometerse de su formación. [...] Haya pues, en cada lugar una o más escuelas, según su población, destinada a enseñar a los niños a leer, escribir, contar, los primeros elementos de la geometría práctica y un catecismo político en que se comprendan todos los elementos de la sociedad en que viven y los beneficios que reciben de ella. Esta enseñanza elemental y tan fácil ha de ser por consiguiente común a todos los ciudadanos: grandes, pequeños, ricos y pobres; deben recibirla igual y simultáneamente. ¿̇No van todos a la Iglesia? ¿Por qué no irían a este templo patriótico? (Cabarrús, 1973, pp. 122-123, 128-129)

\title{
2.1.2. El siglo XIX
}

Ya entrado el siglo XIX, en 1802, Gaspar Melchor $\mathrm{M}^{\mathrm{a}}$ de Jovellanos, escribió "Memoria sobre la educación pública”, o sea, tratado teórico-práctico de enseñanza, con aplicación a las escuelas y colegios de niños, que tuvo gran influencia en la primera Constitución española firmada diez años después de esta obra de Jovellanos, en la que cree firmemente en la instrucción pública como fuente de prosperidad:

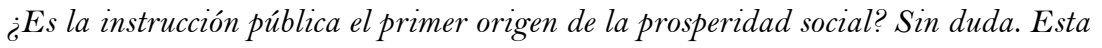
es una verdad no bien reconocida todavía, o por lo menos no bien apreciada; pero es una verdad. La razón y la experiencia hablan en su apoyo. Las fuentes de la prosperidad social son muchas; pero todas nacen de un mismo origen: es la instrucción pública. Ella es la que las descubrió, y a ella todas están subordinadas. La instrucción dirige sus raudales para que corran por varios rumbos a su término; la instrucción remueve los obstáculos que puedan obstruirlos o extraviar sus aguas. Ella es la matriz, el primer manantial que abastece estas fuentes. Abrir todos sus senos, aumentarle, conservarle, es el primer objeto de la solicitud de un buen gobierno; es el mejor camino para llegar a la prosperidad. Con la instrucción todo se mejora y florece; sin ella todo decae y se arruina en un Estado. (Jovellanos, 1956, p. 230)
\end{abstract}

El siglo XIX estuvo repleto de importantísimas normas educativas que albergaban buenas intenciones, pero igualmente lleno de carencias para lograrlas. Así las cosas, las lamentables condiciones que los maestros y los niños y niñas tenían que soportar en los penosos y lúgubres edificios o lugares destinados a ser llamados escuela eran verdaderamente ingratas. Un estudio estadístico fechado en 1870 indica que sólo el 28 por ciento de los locales escolares eran calificados como de buen estado (Viñao, 2006, p. 51). Asimismo, en 1869, se publica el decreto ley de 18 de enero, la norma considerada como "el inicio en España de la legislación sobre construcciones escolares" (p. 52) en el que ya se exponen las calamitosas condiciones estructurales de la instrucción primaria:

\footnotetext{
Apenas hay un pueblo en España que tenga un edificio propio para Escuela; en algunas aldeas los padres no se atreven a enviar a sus hijos a recibir la primera instrucción porque temen catástrofes como las de Ruzafa y Albacete; en muchos puntos el Profesor da las lecciones casi a la intemperie, en patios y corrales, teniendo que suspenderlas los días de lluvia o excesivo frío; en otros sirve de escuela el portal de casa del Maestro, o alguna sala de las Casas Consistoriales. (Preámbulo del Decreto ley de 18 de enero de 1869)
}

Fruto de esa situación y con afán de remediarla, el gobierno requirió a la Escuela de Arquitectura que presentase unos proyectos para construir escuelas, siguiendo un patrón 
determinado con necesidades básicas a cubrir: "Todas las escuelas tendrán precisamente un local para clase o aula, una habitación para el profesor, una sala para biblioteca, y jardín, con todas las condiciones higiénicas que exige un edificio de este género" (Viñao, 2006, pp. 52-53). Sin embargo, de nuevo los nobles deseos chocaban con la realidad, pues esta disposición no tendría efectividad alguna en la práctica por razones políticas y económicas, pero sentaría las bases de los primeros proyectos de edificios escolares y de los primeros libros de arquitectura escolar en España.

Varios intelectuales, básicamente de corte institucionista, expusieron sus ideas en pro de unas escuelas con condiciones higiénicas, técnicas y pedagógicas más adaptadas a la importancia de lo que se trataba en ellas a diario. Uno de los que destacó, entre pocos, fue nada menos que Francisco Giner de los Ríos, el alma de la Institución Libre de Enseñanza (la famosa ILE), que publicó unos breves manuales que recogen sus ideas sobre el edificio escolar (Giner de los Ríos, 1884a, 1884b).

Nuestro país tenía, como denominador común, el concepto de escuela entendido como un centro unitario, regido por el maestro o la maestra, que atendía en una misma estancia al alumnado que tenía edades y niveles diferentes. Si bien es cierto que este tipo de escuela permaneció a lo largo de siglo para prácticamente desaparecer y dar paso a la escuela graduada, extendida y generalizada, cabe decir que este tipo de organización graduada tan arraigada y normalizada es de historia relativamente reciente.

Debemos al Real Decreto de 23 de septiembre de 1898 (año de gran crisis e inestabilidad económica, política y social), y a su posterior desarrollo normativo mediante el Reglamento de 29 de agosto de 1899, el denominado "ensayo" de escuela graduada (era necesario adecuar edificios y revisar la organización escolar con la introducción de varios maestros encargados de un determinado grado cada uno, regidos todos ellos por un director). Un ensayo que tardó años en cuajar y en hacer madurar en la sociedad de finales del siglo XIX unas premisas diametralmente diferenciadas en lo que respecta a cambios organizativos, pedagógicos, didácticos, sociales y económicos en la idea que se tenía de escuela. Y, por supuesto, cambios arquitectónicos.

\subsubsection{Los primeros años del siglo $\mathrm{XX}$}

Entrado el siglo Xx, surgen aportaciones pedagógicas de primer orden a nivel mundial que van a orientar e influir sobresalientemente en el devenir de la enseñanza y, por supuesto, de los edificios escolares en los que se administrará la educación escolar. En este sentido, cabe resaltar que

En los años 1901 y 1907, Decroly funda centros para niños irregulares en Ucle y
Bruselas; en 1902 Adolphe Ferrière funda la primera escuela nueva en Suiza; en
1903, Paulov, en el Congreso Médico Internacional, describe su teoría sobre los
reflejos condicionados e incondicionados; en 1907 la doctora Montessori funda en
Roma las Casa dei Bambini, donde aplica su método; en 1910, Kerschensteiner en
Alemania trabaja en la creación de las Arbeitsschulen (Escuelas de trabajo). Sin
olvidar las Maison des petits también en Suiza de E. Claparède de 1902, o el
trabajo desarrolado por John Dewey o Fröebel en los Estados Unidos. (Carrió,
Domènech y Ramis, 2015, p. 35)

Estas aportaciones y tendencias condicionaron y guiaron el nuevo anhelo educativo, que buscaba que el centro escolar fuese un espacio vital para todos, en el que la acción docente promoviera acciones compensadoras de la injusticia social en un ambiente saludable, pedagógicamente rico y cercano al ideal de que el hombre no puede ser ajeno a la naturaleza. 
A las puertas del nuevo siglo Xx, el ramo de la enseñanza goza ya de un Ministerio creado ad hoc. Ese año fue también el que vio la primera piedra del nuevo formato escolar: la escuela graduada. Viñao (1990) explica que "la primera piedra del primer edificio para escuelas graduadas fue colocada en Cartagena, el 9 de diciembre de 1900, en un acto presidido por García Alix, flamante titular del recién creado Ministerio de Instrucción Pública" (p. 14), pero decimos que tardó en normalizarse la extensión de redes de estos centros, porque no fue hasta bien entrado el nuevo siglo Xx, mediante los Reales Decretos de 30 de marzo y 25 de abril de 1905, cuando la legislación apostaba definitivamente por una extensión de este tipo de centros. La carencia económica para llevar esta importante empresa que cambiaría el panorama educativo de la enseñanza, especialmente en sus etapas primaria y secundaria, propició que la idea tuviese que empezar a materializarse a gran escala durante las dos primeras décadas de la nueva centuria.

Sin lugar a dudas, ese nuevo formato escolar, que llegó para quedarse, condicionaría el quehacer de alumnos, maestros, y evidentemente, de inspectores. Unos inspectores de primera enseñanza consolidados en un cuerpo profesional definido desde su creación en 1849, pero sin una clara inamovilidad en el cargo y destino, dos aspectos que serían determinantes en el devenir de los años y que afectarían de lleno a la supervisión de las escuelas unitarias y las recién creadas escuelas graduadas, en un país que no contaba con los medios adecuados para garantizar trayectos ágiles, pues eran largos y tediosos en demasiadas ocasiones, con necesidad de posada para alojarse durante sus visitas a los centros, para esos inspectores que vivían por y para el florecimiento de la escuela, de quienes Serrano de Haro (1973) escribe sobre "el peregrinar incesante por ciudades y aldeas, enseñando, estimulando, corrigiendo, diciendo a autoridades locales y padres de familia la verdad fecunda de cuánto y cómo tenían el deber de hacer” (p. 791).

De esta forma, con escuelas que albergaban diversos grados y numerosos docentes dirigidos jerárquicamente por un director o directora, se requerían edificios más grandes y con muchos más espacios. Ahí la arquitectura escolar de centros públicos tuvo un momento crucial, especialmente a partir de la segunda década del siglo. Los centros escolares empiezan a construirse en la periferia, para aunar higienismo y mayor disponibilidad de suelo para construir los nuevos colegios públicos. En el año 1920, mediante el Decreto de 20 de noviembre, se crea la Oficina Técnica para Construcción de Escuelas, que estará operativa hasta el año 1936, siendo el organismo responsable de las construcciones escolares durante los años de la dictadura de Primo de Rivera hasta entrada la Guerra Civil, construyendo edificios escolares "sencillos al estilo regionalista racionalista, según un criterio general de modestia en el coste y austeridad en la traza, al mismo tiempo que de higiene y solidez", que debían estar "perfectamente enraizadas en el lugar en que se levantan” tal como argumentó el arquitecto escolar Leopoldo Torres Balbás en unas conferencias dictadas el 20 de febrero de 1933 (Torres Balbás, 1933, p. $57)$.

\subsubsection{La Segunda República}

Proclamada el 14 de abril de 1931, la Segunda República dio un giro definitivo en beneficio de la educación pública. El Gobierno acometió en escasos meses un ambicioso plan de renovación de la educación que se prolongará hasta el bienio azañista, con el apoyo de unas minorías ilustradas y con el respaldo del denominado "regeneracionismo", que apoyará la acción educativa y cultural de los primeros ministros republicanos del 
primer bienio: el deseo de construir más y mejores escuelas para erradicar la ignorancia empezó a ser una realidad, así como la socialización de la cultura mediante la realización efectiva del derecho a la educación y la aplicación del principio de igualdad mediante la “escuela unificada”, fundamentalmente (cfr. Puelles Benítez, 2004, p. 62).

Marcelino Domingo, ministro de Instrucción Pública del Gobierno provisional de la República, encargó al Consejo de Instrucción Pública la redacción de un Programa de Instrucción Pública, lo que actualmente denominaríamos una ley orgánica de educación. Aunque esa ley nunca llegó a ver las páginas de la Gaceta, la redacción del proyecto que Lorenzo Luzuriaga hizo por encargo del Consejo tuvo, sin embargo, una impactante influencia en la posterior Constitución de 1931, e indudablemente, en los planes posteriores al franquismo, sobre todo en la LOGSE y en la LOE.

Luzuriaga, educado en la Institución Libre de Enseñanza, estudió en la Escuela Superior de Estudios del Magisterio y fue un destacado inspector. En su proyecto, basado en la escuela unificada de los tres grados de enseñanza con el fin de evitar que la educación no fuese una barrera para las clases trabajadoras, previniendo que la instrucción primaria se adjudicara a ellas, mientras que la secundaria y la universitaria fuese coto privado de las clases media y alta. Luzuriaga desarrolló el concepto de escuela pública como responsabilidad del Estado, la escuela activa, y abogaba por la educación pública laica o extra-confesional, con neutralidad religiosa, es decir, se rechazaba que la escuela pública enseñara cualquier religión confesional, al entender el asunto propio de la Iglesia y de la familia, aunque no por ello impedía el conocimiento por los alumnos de un fenómeno humano tan importante como es la religión (Luzuriaga, 1931, p. 418). Recomendaba la gratuidad de las enseñanzas primaria, secundaria y universitaria, aunque la falta de recursos provocó que la Constitución republicana de 1931 contemplase únicamente la gratuidad de la primera enseñanza, así como también incorporó muchas de sus ideas, algunas de ellas llevadas al máximo exponente; sirva de ejemplo que Luzuriaga reclamaba neutralidad religiosa en las aulas y la Constitución, en cambio, apostó deliberadamente por la laicidad en su artículo 48 y por prohibir la enseñanza a las órdenes religiosas (artículo 26). Exiliado a Argentina, Luzuriaga falleció en Buenos Aires en 1959.

Es común escuchar bondades pedagógicas de la II República, pero ésta sólo conoció un periodo de relativa estabilidad: el denominado bienio azañista (1931-1933), que fue "un periodo de grandes ilusiones, de importantes proyectos y de notables realizaciones" (Puelles Benítez, 2008, p. 5) en el que otro importante hombre formado en la ILE, catedrático de Derecho Político de las universidades de Granada y Madrid y uno de los teóricos más lúcidos de nuestra historia democrática, Fernando de los Ríos, desempeñó el cargo de ministro de Instrucción Pública y Bellas Artes desde diciembre de 1931 hasta junio de 1933. Su mayor empeño fue desarrollar lo establecido en el artículo 49 de la Constitución republicana, que manda poner en práctica una ley de instrucción pública, y así desarrolló en su ministerio dos importantes obras:

- El proyecto de bases de la enseñanza primaria y de la segunda enseñanza, remitido a la Cámara en diciembre de 1932.

- El proyecto de ley de reforma universitaria, remitido a la Cámara en marzo de 1933. 
De las veintiséis bases dedicadas a la enseñanza primaria, destacaremos la importancia que se da a la educación infantil (con tres tipos de escuelas: maternales para niños de dos a cinco años; de párvulos, para los de cinco a ocho; y escuelas primarias, para los de ocho a catorce) y la atención a la educación especial (con una moderna organización de las enseñanzas especiales para sordomudos, ciegos y deficientes mentales), un amplio y rico currículo, una articulación interna con la enseñanza secundaria, atención al mundo rural con un Patronato de Misiones Pedagógicas y una potente formación de los maestros.

Sin embargo, también hubo críticas durísimas a lo establecido en la Constitución republicana de 1931, aprobada el 9 de diciembre de ese año, que estaría vigente hasta el final de la Guerra Civil, en 1939; especialmente criticados fueron diversos artículos conflictivos de la Carta Magna republicana, como el artículo 3, que declaraba que "el Estado español no tiene religión oficial”, así como también el artículo 26, que expresaba numerosas acciones encaminadas a eliminar prebendas del clero, que fueron fundamentales en la consideración laica de la enseñanza en particular, y del conjunto de elementos públicos que regían la sociedad.

El gobierno de Manuel Azaña dio prioridad a la educación, ante la preocupante tasa de analfabetismo (entre un 30 y un 50 por ciento del total de la población, no sólo niños). Apostó por un decidido plan de inversiones en infraestructuras (se crearon miles de escuelas) a la vez que se puso en práctica un elenco de métodos pedagógicos basados en los preceptos institucionistas de la ILE para llevar el aliento del progreso a todos y cada uno de los ciudadanos del país.

Cuando en febrero de 1936 triunfó el Frente Popular con un programa educativo que significaba el retorno a los esperanzadores proyectos del bienio azañista y al influjo de la ILE, la Guerra Civil estaba a sólo unos meses de estallar.

\subsubsection{La Guerra Civil y el Franquismo}

La barbarie de la Guerra Civil se encargó de desmantelar el proyecto educativo republicano, y durante los cuarenta años de dictadura franquista fueron muchos y variados los acontecimientos que marcaron la evolución de la arquitectura escolar. El golpe de Estado que Francisco Franco asestó al legítimo gobierno republicano elegido democráticamente en 1936, que desembocó en la Guerra Civil y su consiguiente victoria y consolidación, supuso un evidente y verdadero retroceso en los avances pedagógicos derivados del primer periodo de la Segunda República, ya que obviamente el proyecto educativo implantado por Franco a partir del mismo 1936 es antagónico a aquel proyecto republicano que Luzuriaga y Fernando de los Ríos trataron de arraigar. No es momento de analizar la contienda, ni nuestro objetivo pormenorizar todas las características de la educación y arquitectura escolar durante los largos años de la dictadura de Franco hasta su muerte en noviembre de 1975, pero en lo referido a la construcción de la educación como derecho fundamental de los individuos, es innegable que no todo fue absolutamente negativo, sin dejar por ello de ser lamentable la desmantelación de la obra republicana, el retroceso en materia de la infausta depuración de profesorado en todos sus grados (igual que como lo fue también el resto de profesionales de la enseñanza, por las llamadas Comisiones de depuración, que también afectaron directamente, al haber una de las citadas comisiones destinadas ex profeso a ello, a los profesores de Escuelas Normales y a los inspectores), así como de los libros de texto y de las bibliotecas escolares, la laxa formación científica de los maestros, el retorno a la estructura bipolar y al elitismo, sobre todo el universitario, el exacerbado 
centralismo controlador, el obligado integrismo católico tradicional y el poder de la Iglesia o, por no seguir citando en demasía, el culto al caudillo, la elaboración de una pedagogía basada en la autoridad, el orden, la jerarquía, la disciplina y el castigo físico y moral, impuestos por el Régimen. Durante casi cuarenta años de primacía franquista hubo en España numerosas leyes de educación, muchas de ellas sectoriales; pero la única que tuvo anhelo de mejorar la totalidad del sistema educativo desde una perspectiva modernizadora fue la Ley General de Educación , popularmente conocida como Ley Villar, en honor al ministro del ramo que la impulsó, José Luis Villar Palasí. Durante los veinte años que estuvo en vigor hasta que la LOGSE la derogó, se hizo una apuesta decidida por la construcción, aumento y mejora de las construcciones escolares.

\subsubsection{El restablecimiento de la democracia}

Muerto Franco y promulgada la vigente Constitución de 1978, el auge de la ideología progresista promovió gobiernos que legislaron teniendo en cuenta los postulados institucionistas y tomando como base muchas de las apuestas llevadas a cabo durante el primer bienio de la Segunda República: la LOGSE y la LOE son un claro ejemplo. Sin embargo, la pugna y alternancia en el Gobierno de tendencias conservadores y progresistas ha conducido a nuestro país a una colección de leyes que derogan las anteriores del gobierno saliente. Además, la descentralización propició que los gobiernos autonómicos hayan tomado muchas competencias en materia educativa $\mathrm{y}$, por supuesto, entre ellas está la de la planificación escolar y edificación de centros educativos públicos. A día de hoy, tras una retahíla de leyes orgánicas estatales de educación, seguimos pendientes de una nueva reforma de la última que se proclamó hace sólo tres años. Veremos qué dice la historia de todo esto. Mientras, los gobiernos autonómicos, que también van sucediéndose muy rápidamente sin que se puedan consolidar políticas más allá de los pocos años en los que están en el poder, tratan de adaptarse a la globalización, al flujo migratorio y a la era digital en la creación de escuelas e institutos públicos que, a decir verdad, no parecen que sean del siglo XXI.

\subsection{Un repaso al conocimiento académico}

Cabanellas y Eslava (2005, p. 29) hablan del relativo olvido al que se ha relegado la cuestión del "espacio vital", pues el colegio es uno de los principales territorios vitales de la infancia. En esa misma obra, se expone que:

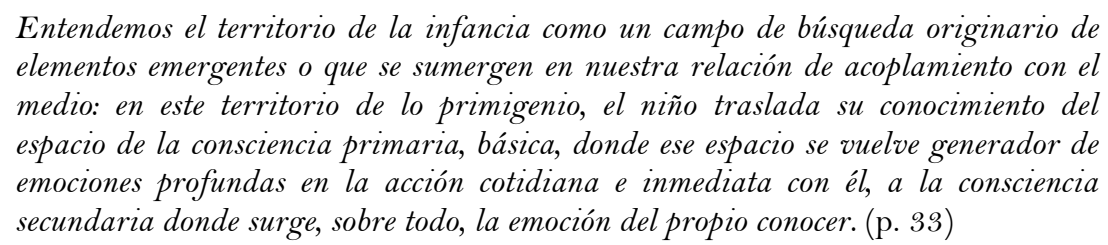

En una obra que analiza y expone las bases de la construcción de escuelas e institutos norteamericanos, Kliment (2001, pp. 11-12) habla del reto de las escuelas en relación con el aumento de la demanda educativa, por lo que el reto es para administradores, profesorado y arquitectos, a la vez que las escuelas experimentan e implementan técnicas pedagógicas inclusivas con alumnado de educación especial que exigen nuevos tipos de ambientes físicos.

Además, a las puertas de nuestro siglo, en 1992 el experto en arquitectura escolar estadounidense C. William Brubaker, que diseñó más de 200 escuelas y "tomaba como a sus clientes no sólo a la Administración educativa, sino también a los niños y 
profesores"(cfr. Kamin, 2002, s.p.), expuso un listado de los cambios significativos en los programas y políticas escolares que promueven avances en el diseño de centros educativos, que resumimos en la tabla 1.

Tabla 1. Cambios significativos en programas y políticas escolares que influencian avances en el diseño de centros educativos según Brubaker

\begin{tabular}{|c|c|c|}
\hline CAMBIO & ANTES (TRADICIONALMENTE) & AHORA \\
\hline Cambios en el currículo & $\begin{array}{l}\text { Basado en libros y clases } \\
\text { estándar }\end{array}$ & $\begin{array}{l}\text { Con métodos de enseñanza y } \\
\text { aprendizaje fundamentados en } \\
\text { nuevas tecnologías que demandan } \\
\text { flexibilidad de espacios }\end{array}$ \\
\hline Espacios especializados & $\begin{array}{l}\text { Había numerosas clases } \\
\text { estándar }\end{array}$ & $\begin{array}{l}\text { Más clases diseñadas para } \\
\text { asignaturas diferentes, como la } \\
\text { tecnología o la informática }\end{array}$ \\
\hline Educación especial & $\begin{array}{l}\text { Se construían centros de } \\
\text { educación especial para alumnos } \\
\text { con necesidades específicas }\end{array}$ & $\begin{array}{l}\text { Aprenden en centros ordinarios } \\
\text { mediante la educación inclusiva }\end{array}$ \\
\hline Variedad & $\begin{array}{l}\text { Las edificaciones escolares } \\
\text { tenían el formato de barracones } \\
\text { o bloques rectangulares }\end{array}$ & $\begin{array}{l}\text { Hay más elección de edificios } \\
\text { escolares, incluidos distintos } \\
\text { tipos de escuela }\end{array}$ \\
\hline Tamaño de las aulas & $\begin{array}{l}\text { Estaban abarrotadas, con } \\
\text { incluso } 40 \text { alumnos o más. }\end{array}$ & $\begin{array}{l}\text { El profesorado y los padres han } \\
\text { exigido ratios más reducidas }\end{array}$ \\
\hline Tamaño de la escuela & $\begin{array}{l}\text { Las escuelas se ampliaban con } \\
\text { extensiones de las existentes }\end{array}$ & $\begin{array}{l}\text { El tamaño ha sido reevaluado. } \\
\text { Las escuelas más pequeñas tienen } \\
\text { una escala más «humana» y son } \\
\text { más flexibles }\end{array}$ \\
\hline Regulaciones & $\begin{array}{l}\text { Las edificaciones escolares } \\
\text { estaban menos reguladas }\end{array}$ & $\begin{array}{l}\text { El diseño de los nuevos edificios } \\
\text { escolares es más complejo por } \\
\text { diversas regulaciones, como por } \\
\text { ejemplo el acceso a personas con } \\
\text { discapacidades, seguridad contra } \\
\text { incendios, códigos del edificio, } \\
\text { uso de la energía, calidad del aire, } \\
\text { regulaciones de zonas costeras, } \\
\text { impacto ambiental y exigencias } \\
\text { del área }\end{array}$ \\
\hline Costes & $\begin{array}{l}\text { Los costes de alumno por año } \\
\text { eran altos por el aumento de } \\
\text { costes operativos y de } \\
\text { mantenimiento }\end{array}$ & $\begin{array}{l}\text { Los costes de alumno por año son } \\
\text { menores por la reducción de los } \\
\text { costes operativos y de } \\
\text { mantenimiento }\end{array}$ \\
\hline Escuelas de todo el año & $\begin{array}{l}\text { Los centros educativos se } \\
\text { usaban únicamente durante los } \\
\text { nueve meses del año escolar }\end{array}$ & $\begin{array}{l}\text { Las escuelas pueden estar } \\
\text { abiertas los doce meses del año y } \\
\text { ser usadas por la comunidad local } \\
\text { durante los meses no académicos }\end{array}$ \\
\hline Enlaces electrónicos & Las escuelas estaban solas & $\begin{array}{l}\text { Pueden conectarse a otras } \\
\text { escuelas, oficinas administrativas, } \\
\text { bibliotecas, facultades y } \\
\text { universidades, y otras ciudades y } \\
\text { países, por ejemplo a través de } \\
\text { internet }\end{array}$ \\
\hline Eficiencia energética & $\begin{array}{l}\text { Los edificios escolares tenían } \\
\text { paredes delgadas, pobremente } \\
\text { aisladas térmicamente }\end{array}$ & $\begin{array}{l}\text { Las escuelas tienden a ser } \\
\text { «verdes» y bien aisladas, bien } \\
\text { ventiladas y energéticamente } \\
\text { eficientes. }\end{array}$ \\
\hline
\end{tabular}

Fuente: Elaboración propia a partir de Curtis (2003, p. 9). 
Sin embargo, tal como prosigue Curtis, ya han pasado años desde este listado y siguen los cambios en tendencias políticas y en la educación misma que afectan al diseño de las escuelas. Sin embargo, dice Curtis, parece que las tecnologías han condicionado mucho, pero también la relación de la comunidad local con la escuela, que considera "vital para su éxito" a la par que realza un elemento clave en la nueva configuración de los espacios escolares: la flexibilidad, ya que, tal como indica, es:

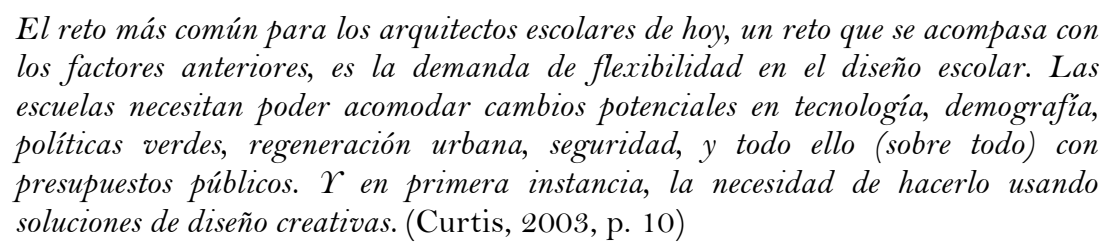

Dice Sarramona (2002) que una de las prioridades que debe marcarse el proyecto educativo de un centro escolar que quiera favorecer especialmente la innovación es, entre otros, el hecho de "convertir el centro y sus alrededores en entornos más verdes, saludables y sostenibles" (p.86). En esta misma obra, se apuntala uno de los pilares fundamentales de la función socioeducativa del territorio para lograr una mayor vertebración entre la escuela y el entorno mediante la necesaria reestructuración del territorio:

Ni la ciudad ni cualquier comunidad rural o urbana puede ser educadora si el entorno no ofrece posibilidades y experiencias educativas relevantes. Por ello, hay que repensar y reestructurar el modelo de territorio con la creación de tiempos y espacios que faciliten el intercambio entre las diversas generaciones; recursos e infraestructuras culturales, deportivas y lúdicas: y oportunidades para que los niños y niñas puedan educar la mirada, experimentar con objetos, explorar nuevas realidades y fantasías, o proyectar sus deseos corporales y musicales. Todo ello en un ecosistema más habitable y sostenible. (p. 109)

Es cierto que uno de los desiderátums más notables de la Pedagogía es aunar armónicamente el espacio escolar con el entorno que lo rodea (escuelas con zonas ajardinadas, con luz natural, espaciosas, etc.), pero más importante es todavía que eso no quede en una mera utopía idealista y se sigan construyendo escuelas grises, cerradas a cal y canto con tremendos muros, con escasa luz natural, mal orientadas, con aulas diminutas y espacios angostos, con carencias en espacios más que significativas, etc. En pleno siglo XXI, aún muchos añoramos las tendencias institucionistas que nos regaló la ILE, hace ya casi un siglo y medio, con sus aportaciones higienistas y sus escuelas abiertas al ideal de que el contexto educa más que el texto. Sin embargo, parece que hace cien años que estamos pugnando por lograr escuelas más abiertas al entorno, escuelas que eduquen más allá de la acción docente impartida en las cerradas aulas.

Coleman (1985, pp. 527-532) estipula que la escuela debe estar vinculada al entorno, ya que no sólo pretenden el desarrollo individual, sino que también buscan influir en las dimensiones social, cultural y económica de las comunidades a las que pertenecen, por lo que contribuyen al desarrollo colectivo. Tanto es así, que entendemos que con una organización escolar abierta a la comunidad, pueden ser más provechosas a ésta y viceversa. En este sentido, el espacio que delimita el centro escolar, con sus características arquitectónicas, sus posibilidades didácticas aumentarán o se reducirán en función de cómo se ha planificado y construido el centro escolar.

La previsiones de población, la globalización y la gran reforma educativa que concretó la LOGSE en 1990 mediante la nueva ordenación del sistema educativo español promovió 
que la planificación escolar tomase un rumbo distinto al que se había marcado hasta la fecha desde el modelo franquista. Se rescataba el modelo comprehensivo e integrado, basado en el los principios de justicia social, equidad, calidad e igualdad de oportunidades para todos, universalizando la enseñanza secundaria que, hasta la fecha, no tenía carácter obligatorio, mediante la configuración de una enseñanza básica, obligatoria, gratuita y común a todos desde los seis hasta los dieciséis años. Cierto es que, según nuestro criterio, no se logró como se esperaba lo que Viñao (2002, p. 59) define como esa "naturalidad en la prolongación natural de la primaria" hacia la secundaria, pues el cambio de etapa requería (aún lo exige a día de hoy) que los alumnos que terminan la Educación Primaria en las escuelas públicas tengan que marcharse a un nuevo centro (el instituto de Educación Secundaria) para cursar allí la segunda (y última) etapa de las enseñanzas obligatorias. Esto ha propiciado la construcción de numerosos centros educativos desde los años noventa del siglo pasado hasta la actualidad, hecho que tiene un enfoque particular en cada comunidad autónoma a tenor de la descentralización acaecida fundamentalmente en los años noventa del pasado siglo, mediante la transferencia educativa por parte del Ministerio de Educación a los gobiernos autonómicos, que son los encargados desde entonces de la planificación y ejecución de los edificios escolares, en estrecha colaboración con los ayuntamientos.

Un año antes de la promulgación de la famosa y mencionada Ley socialista, en 1989, siendo Javier Solana el ministro de Educación y Ciencia, se publicó el Libro blanco para la reforma del sistema educativo (MEC, 1989), que servirá de base para la citada Ley, en cuyas páginas se apuesta "una tipología de centros que será bastante diferente a la actual” (MEC, 1989, p. 291) y, consecuentemente la planificación de una nueva red de centros basada simultáneamente en tres criterios:

1. Garantizar la igualdad de oportunidades educativas para todos los alumnos mediante la aproximación de la oferta educativa a todos los núcleos de población, especialmente en las zonas rurales.

2. Programar los nuevos centros con unas dimensiones apropiadas para utilizar adecuadamente los recursos disponibles, asegurar un buen funcionamiento educativo y desarrollar una enseñanza de mayor calidad.

3. Aprovechar los actuales centros y utilizar lo más eficientemente posible los recursos humanos y materiales existentes. (p. 290)

Quedaba claro que se la educación escolar se proponía un revulsivo para ofrecer equidad, nuevos centros con "dimensiones apropiadas" (concepto verdaderamente subjetivo e interpretable) y aprovechar los centros y recursos existentes. Sin embargo, la empresa no se antojaba sencilla. En ese escenario, Gómez Dacal (1992) presentaba una obra en la que hablaba de centros educativos eficientes, a la vez que cuatro años después publicaba un completo curso de organización escolar y general (Gómez Dacal, 1996); en ambas obras se remarca el valor de las relaciones entre el centro escolar y la comunidad en el que éste se imbrica. Así, son muchas las voces autorizadas que exigen que el centro escolar sea un espacio que fomente la colaboración, la comunicación y la exploración en un entorno seguro, espacioso y hermoso: "la estética es también un valor educativo", nos recuerda Sarramona (2002, p. 86).

En definitiva, concluimos este epígrafe a modo de síntesis, recurriendo a las palabras de Sureda García cuando resalta:

La importancia de la función social de la escuela, el valor que tiene el hecho de disponer de edificios escolares dignos y adecuados haciendo publicidad del 
compromiso de las autoridades de corregir el grave déficit de edificios específicamente dedicados a escuela, con buenas instalaciones, condiciones higiénicas, ventilación e iluminación adecuadas, patios y espacios de juego y comedores, era uno de los objetivos de la modernización educativa del país. ra no se podía seguir haciendo escuela en cualquier habitáculo. Los edificios adquirieron identidad arquitectónica propia y se convirtieron en la representación icónica de la valoración que la escuela debía tener. Una valoración que impulsaron en España todas las corrientes regeneracionistas desde finales del siglo XIX y que llegará a su máximo grado durante la II República. (Sureda García, 2015, p. 18)

\section{Método}

Esta investigación se ha implementado durante el año 2016 y se ha concretado en un estudio de corte cualitativo, con base hermenéutica, a través de la técnica de la entrevista. Queríamos conocer la opinión de diversos informantes relevantes sobre la arquitectura escolar, y a partir del análisis de los datos obtenidos, proponer sugerencias de mejora en la planificación y construcción de edificios escolares públicos. Para ello, la muestra intencional inicial fue planificada para contar con dieciséis personas de cuatro colectivos (arquitectos, directores de centros educativos públicos, inspectores de educación y responsables de la Administración), que fueron invitados formalmente a participar como informantes (fuentes primarias) en la investigación.

Para seleccionar la muestra de informantes, utilizamos la técnica denominada muestreo de bola de nieve mediante la cual un participante conduce a otro participante como una bola de nieve. Indican Maykut y Morehouse (1999, p. 68) que "para conseguir una variación máxima, es aconsejable que el investigador utilice la técnica del muestreo de bola de nieve para localizar participantes o escenarios muy diferentes a los primeros. De este modo, el muestreo de máxima variación es emergente y secuencial (Lincoln y Guba, 1985)". Este hecho, que nos funcionó muy bien porque pudimos agrupar a distintos expertos, como si de ampliar el tamaño de la bola de nieve se tratase, coadyuvó a poder contar con la requerida variabilidad para disponer de bastantes informantes, todos con amplia y reconocida experiencia y suficientes conocimientos sobre el objeto de estudio de esta investigación.

La idea era disponer de una muestra suficientemente considerable para constatar si sus aportaciones confluían en una misma línea común o si, por el contrario, había disparidad de opiniones, dado que los informantes proceden de diversos colectivos profesionales y de diferentes lugares de España. Por eso, nuestra planificación consideró invitar a cuatro o cinco informantes de cuatro grupos profesionales sustantivos en la gestión educativa no universitaria:

- En primer lugar, los arquitectos, que son los expertos en el diseño y desarrollo de la construcción escolar.

- Por otro lado, los inspectores de educación, que mediante su consideración de autoridad pública y la atribución legal de la visita tienen la ocasión de supervisar multitud de centros educativos y, cumpliendo con una de sus funciones establecidas en la ley, pueden proponer mejoras a través de sus informes técnicos elevados a la Administración.

- Un tercer colectivo fue el de los directores, tanto de escuela pública como de instituto, que en su doble condición de profesores y directivos conocen de 
primera mano las necesidades del claustro docente y las fortalezas y debilidades de las infraestructuras de sus centros para potenciar una mejor didáctica de todo el profesorado, así como pueden poner de manifiesto a los inspectores de Educación o directamente a la Administración las necesidades de los centros.

- Por último, y no por ello los menos destacados, los responsables políticos de la Administración educativa, que son los que en definitiva planifican, legislan y condicionan las decisiones más importantes en relación con la edificación de los colegios e institutos públicos.

En nuestro afán de albergar pluralidad de percepciones, tanto por las diferentes ocupaciones de las personas informantes como por el impacto que pueden tener en la toma de decisiones relacionadas con los edificios escolares, no hemos acotado el estudio a nuestra comunidad autónoma (Islas Baleares) sino que los informantes invitados a participar son de distintos enclaves geográficos españoles. Esto además ha propiciado, sin intención ni afán de generalizar el estudio ni sus conclusiones a todas las realidades del Estado español, que numerosos puntos de vista expertos, procedentes de variados lugares del país, se han expresado entorno a una investigación cuyo objetivo principal es conocer diversas percepciones de profesionales relacionados con la arquitectura escolar para proponer mejoras a raíz de sus aportaciones.

Cuatro de los informantes contactados, de distintos colectivos, no contestaron o bien declinaron participar (sólo un inspector de Madrid nos escribió excusándose por su apretada agenda de trabajo, sintiendo no poder sumarse a este proyecto), ya que los tres restantes (una asociación de directores de instituto, un estudio de arquitectura y responsables de una Administración) no llegaron a contestar, pese a que reiteramos nuestra invitación al ver que no obteníamos respuesta de todos.

Así, finalmente, tal como detallamos en la tabla 2, la muestra estructural de los informantes que participaron en el estudio empírico se configuró con catorce informantes (seis de ellos, mujeres: dos arquitectas y dos directoras, una inspectora y una responsable política de la Administración) procedentes de nueve comunidades autónomas, que amablemente han aportado sus percepciones a la investigación.

Tabla 2. Muestra estructural de informantes en el estudio empírico de la investigación

\begin{tabular}{ll}
\hline \multicolumn{1}{c}{ PROFESIÓN } & \multicolumn{1}{c}{ COMUNIDAD AUTÓNOMA } \\
\hline 1 Arquitecto & Islas Baleares \\
1 Arquitecta & Comunidad de Madrid (capital) \\
1 Arquitecto & Andalucía \\
1 Arquitecta & Cataluña \\
\hline 1 Directora escolar & Galicia \\
1 Directora escolar & Cataluña \\
1 Director de instituto & Región de Murcia \\
\hline 1 Inspector de educación & Islas Canarias \\
1 Inspector de educación & Comunidad Valenciana \\
1 Inspector de educación & Andalucía \\
1 Inspectora de educación & País Vasco \\
\hline 1 Responsable de la Administración & Islas Baleares \\
1 Responsable de la Administración & Comunidad de Madrid \\
1 Responsable de la Administración & Cataluña \\
\hline
\end{tabular}

Fuente: Elaboración propia. 
Estos mencionados informantes, que han participado voluntariamente y con gran interés en la temática planteada, fueron contactados a través de un correo electrónico, en el que se les exponía el objeto de la investigación, y la invitación a participar contestando a tres preguntas, solicitando sus respuestas por escrito expresadas lo más concisamente posible a las cuestiones planteadas, siempre teniendo en cuenta que hablamos desde el punto de vista arquitectónico, de creación de espacios para el aprendizaje y el desarrollo integral, aspectos que sin duda condicionan la enseñanza y la gestión escolar, a la vez que son elementos clave en la escolarización de millones de niños y jóvenes. Dichas cuestiones quedan reflejadas en la tabla 3.

Tabla 3. Preguntas planteadas a los informantes de la investigación

- ¿Cree usted que en el diseño y construcción de los centros escolares públicos se sigue algún modelo o patrón definido?

- ¿Ha detectado alguna carencia o aspecto negativo en el diseño y construcción de los centros escolares públicos?

- ¿Podría proponer alguna mejora en el diseño y construcción de centros escolares públicos?

Fuente: Elaboración propia.

Cabe resaltar que los expertos contactados como fuentes primarias fueron informados pertinentemente de que todos los datos que aportarían iban a ser tratados anónimamente, a la vez que les garantizamos la confidencialidad en orden a que ningún dato ofrecido pudiese identificarles o comprometerles. Así lo hemos cuidado en todo momento, tanto en el diseño, en la implementación y en la redacción del informe final de la investigación que aquí presentamos.

Afortunadamente, en el transcurso de unas pocas semanas recibimos las respuestas por escrito de todos los expertos informantes a través del correo electrónico, hecho que propició que pudiésemos empezar con el análisis de los datos de modo claro y definitivo.

\section{Resultados}

A tenor de la relevancia que tiene el formato arquitectónico escolar en la actividad diaria que se desarrolla en los centros públicos, las catorce personas informantes aportaron múltiples consideraciones, en respuesta a las tres preguntas que les planteamos. Seguidamente exponemos algunas evidencias de manera ordenada, según las preguntas planteadas en la investigación.

\subsection{Resultados en relación con la primera pregunta}

Sobre la primera cuestión, basada en si creen que se sigue un modelo o patrón definido en el diseño y construcción de centros escolares públicos, una arquitecta catalana reforzó la idea de que "los centros educativos se hacen a partir de unos parámetros muy ajustados, que vienen estipulados por la Generalitat", a la vez que dice que "las directrices las marcan los políticos, y luego los arquitectos tratan de hacer lo mejor que está en sus planes a partir de unas especificaciones establecidas por el contratante, que insisto que en nuestro caso es el gobierno de la Generalitat, que no se pueden modificar ni un ápice".

Una inspectora expuso que:

En cada momento se nota la influencia de las corrientes pedagógicas en boga. Así, tras la Ley Villar Palasí se construyeron un tipo de centros pensados para llevar 
adelante sus principios. Las diversas leyes educativas han supuesto un diseño concreto de centros, aunque en la mayoría se centran en aularios, tipo empresa de la sociedad industrial, y algunos, unos pocos lugares comunes como la biblioteca, el gimnasio y los patios. La ubicación de los centros se hace, en el último año sobre todo, en las afueras de las ciudades y los pueblos, en función de un menor coste del terreno, obligando a desplazamientos inútiles y a las desvitalización del centro, del que desparecen los niños y niñas.

No pasa esto con las iglesias y los bancos. Alguien dijo que el día que las escuelas ocupen los lugares que ocupan éstos, ese día creeremos que la educación importa.

Resulta curioso que se vea en distintos sitios, de condiciones climáticas muy diferentes, exactamente el mismo centro. Se replica el mismo diseño en sitios diferentes.

Son muy interesantes las construcciones de la época de la república como ejemplo del valor que se daba a la educación, contrastables con las que construyó el franquismo.

En el País Vasco, las llamadas "Escuelas de barriada" fue otro ejemplo de construcciones para dar respuesta a una situación concreta y hacerlo con dignidad.

La respuesta de un arquitecto fue muy ilustrativa:

La aparición de modelos o patrones definidos en las soluciones arquitectónicas no responde generalmente a una decisión premeditada. Si enfocamos la arquitectura en sus fuerzas generadoras podemos plantear:

\section{$1^{\circ}$ ARQUITECTURA RACIONALISTA}

La arquitectura desarrollada en el último siglo, desde las décadas 10-20, se denomina racionalista. La búsqueda de soluciones científicas a necesidades sociales es el motor de la arquitectura desde este momento histórico.

Mencionaría referido a la arquitectura escolar de esta primera época el concurso para la Petersschule Basilea año 1926 de los arquitectos Hans Meyer y Jakob Wittwer y La Escuela al Aire Libre (Openluchtschool) año 1930 de los arquitectos Johannes Duiker y Bernard Bijvoet.

En estos ejemplos, aún hoy en día referencia de muchos arquitectos, temas como la generación de espacios libres para el recreo o la educación física, las zonas comunes (comedores, recepción...), la preocupación por la edificación saludable (ventilación, iluminación...) sirven de base a lo que en los programas actuales de arquitectura se define como Funcionalidad y racionalidad de los espacios.

\section{$2^{\circ}$ ARQUITECTURA SOCIAL}

La edad contemporánea que nace es un formulación teórica, entre el siglo XVIII y XIX, aunque cristaliza en el siglo XX con el catalizador de la I Guerra Mundial. Tras el impulso de la revolución francesa y la independencia de los países americanos aparece un nuevo sujeto político, el ciudadano, con derechos y deberes. Un derecho ciudadano es la educación. En la actualidad la población se concentra mayoritariamente en núcleos urbanos, por lo que la mayoría de edificios educativos se pueden agrupar en: Edificios históricos del siglo XIX, primeras escuelas e institutos de cada capital de provincia etc. y en edificios modernos asociados a barrios, con una arquitectura desarrollada en los últimos 60 años con tipologías de parcelas, urbanismo, accesos similares que vienen a desarrollar sobre el terreno la universalización de la educación. Se comienza a hablar de ratios de estudiantes por aula, superficies por actividad, etc.

Por otro lado la promoción pública de estos equipamientos los obliga a la economía en la solución, tanto en la construcción de los mismos como en la durabilidad y mantenimiento de la arquitectura. Por último los cambios sociales, a los que la escuela no es ajena, obliga a incluir aspectos como la conciliación familiar, la apertura de centros fuera de horario escolar etc. que repercuten en el programa.

Aunque la variedad formal en la solución sea abundante, la construcción en base a programas similares desde hace cien años y la estabilidad social de una población 
urbana desde hace sesenta producen una repetición de organigramas, esquemas formales, soluciones de funcionalidad que se muestran eficientes y garantizan una formalización correcta de la arquitectura.

Un director de instituto respondía que:

A lo largo del tiempo, sí se observa la repetición de modelos, hasta el punto de que, en algunos casos puede determinarse con poco margen de error la fecha (década) de construcción del edificio de que se trate. Estos modelos recibian las correspondientes adecuaciones en función del solar disponible, pero básicamente eran iguales.

No obstante, en los últimos años, al menos en la Región de Murcia, y en los últimos edificios educativos construidos, se observa una tendencia al diseño original. Un intento de individualizar arquitectónicamente.

Hablo de los centros de primaria y secundaria. La Universidad sí se ha caracterizado por edificios singulares para cada Facultad, más o menos originales, más o menos acertados y adecuados a su función, pero arquitectónicamente independientes.

Un responsable político de la Administración indicó que “Creo que sí, pero no existe un modelo único sino bastante flexible que sigue un patrón de condiciones de contrata en el que se señalan los elementos del proyecto necesarios en el edificio escolar”.

Una directora escolar no aprecia un patrón definido en la actualidad, pero sí lo valora en edificios de hace cuatro décadas:

Según mi opinión los centros escolares se adaptan a la zona y al número de alumnos/as que previsiblemente darán cabida. De hecho en la zona que yo conozco en Galicia, en los últimos 25 años se construyeron varios centros de Educación Infantil y Primaria, IES, ... todos ellos diferentes. Antiguamente, en los años setenta del siglo pasado sí se seguía un patrón definido al ser todos los centros educativos (concentraciones escolares) prácticamente iguales.

Por su parte, un inspector expone que:

Más que un patrón vinculado a características singulares o propias del diseño, pudiera considerarse la determinación del marco normativo que regula los requisitos mínimos de los centros. Esto es, el Real 132/2010, de 12 de febrero (BOE de 12 de marzo), por el que se establecen los requisitos mínimos de los centros que impartan las enseñanzas del segundo ciclo de la educación infantil, la educación primaria y la educación secundaria. Luego este marco quizás pudiera considerarse como patrón de la estructura o de los proyectos. Por otra parte, se advierten también centros con una construcción replicada en distintas zonas o localidades; si bien las razones parecen más debidas a la expansión de las construcciones escolares en épocas que registraban una alta demanda de puestos escolares o de adecuación de edificios con mucha antigüedad.

Otro responsable político de la Administración defendió la idea de que:

estamos asesorados por arquitectos, arquitectos técnicos, por jefes de servicio de obras $y$ proyectos con alta cualificación (...) Es cierto que en ocasiones hay errores de diseño o construcción, pero la Administración se encarga de repararlo a la mayor celeridad posible, de eso estoy convencido.

Otro inspector indica, al ser preguntado por si aprecia un modelo o patrón definido en las construcciones escolares, argumenta:

Considero que no. Actualmente existen centros escolares que con distintos diseños, siendo en algunos casos, construcciones escasamente prácticas y poco adaptadas a las características y peculiaridades que deben poseer los centros educativos (espacios diáfanos, con alta luminosidad natural, sin barreras arquitectónicas, etc.). En los años 70 y de acuerdo a las "medidas urgentes" relacionadas con la educación, la mayoría de los centros educativos tenían la misma construcción y diseño, pero 
posteriormente, han proliferado diferentes y variopintas edificaciones sin un "común denominador", primando la estética frente a otros indicadores.

Una arquitecta se mostró convencida de que:

El diseño de construcción de centros escolares sigue una normativa que depende de la Comunidad Autónoma. Las normativas autonómicas definen unos tamaños mínimos pero no habla de configuración espacial, generalmente en los concursos públicos se valora más la economía de espacios y presupuesto que la propuesta "conceptual" por ese motivo los edificios escolares se suelen parecer bastante. En algunas comunidades autónomas se exige un minimo de vegetación en los patios, de zonas deportivas etc. En otras comunidades estos asuntos no se contemplan.

Otro inspector también se refirió a una norma vigente ya citada por otro inspector, a la vez que expone su respuesta:

Parto de la premisa de que son centros de enseñanza obligaría (E. Primaria y ESO). En este caso el modelo tiene como referencia el Real Decreto 132/2010, de 12 de febrero, por el que se establecen los requisitos mínimos de los centros que impartan las enseñanzas del segundo ciclo de la educación infantil, la educación primaria y la educación secundaria. Este Real Decreto es completado con la normativa sobre edificación y en alguno casos con normativa autonómica, por ejemplo en la Comunidad Valenciana se decidió que en los centros de Primaria se construyese un trinquet para fomentar el deporte de la pilota valenciana. Este diseño en muchas ocasiones se somete a consulta de la comunidad educativa o del ayuntamiento quienes plantean algunas propuestas que en algunas ocasiones son atendidas: capacidad del comedor, etc. En muchos casos es la propia administración quien al licitar una obra (o varias) establece algunas condiciones no contempladas en la normativa vigente: casa para el conserje, aparecimiento para docentes, amplitud de ventanas acristaladas para aprovechar la luz en una zona como la valenciana, etc.

\subsection{Resultados en relación con la segunda pregunta}

Sobre la segunda cuestión, relacionada con las carencias o aspectos negativos en la construcción de los centros públicos, un arquitecto que ejerce en Palma de Mallorca remarcó que:

En general, más que una carencia o aspecto negativo, sí una cierta autocomplacencia en la adopción de soluciones programáticas que permiten al arquitecto centrarse en aspectos más formales donde la innovación o simplemente la moda produce más satisfacción inmediata.

Otro arquitecto madrileño destacó como aspecto negativo que:

No podemos reunirnos previamente con los usuarios de los centros que vamos a proyectar, porque sería muy interesante saber sus opiniones, críticas, etc. Deberíamos poder tener la ocasión de coincidir con profesores, directores, incluso con padres y alumnos, por qué no, y otros usuarios. Ellos son los que están día a día en las escuelas y podrían transferirnos las fortalezas y las debilidades que observan en los edificios. Nosotros no sabemos de pedagogía, pero diseñamos para que se haga pedagogía en nuestros proyectos, en las aulas y diversos espacios que proponemos. Además, y esto me parece muy importante, diseñamos ahora para la educación de muchos años que han de venir, de los cuales no sabemos nada o, a lo sumo, podemos aventurar algo. ¿Quién me dice a mí qué conviene aquí o alli? Yo no sé de cómo va a usar el gimnasio el profesor, ni si el espacio que dibujo para la biblioteca quedará obsoleto en poco tiempo. Ahí querría oír la voz de los que viven en las escuelas año tras año. Sería muy beneficioso tanto para nuestros proyectos como para ellos una vez estuviesen materializados. 
Una directora escolar catalana fue muy crítica con la gestión política en materia de arquitectura escolar, al desarrollar la idea de que:

Lo más grave es que hay muchos errores que se van repitiendo a lo largo de los años en diferentes centros, y de eso parece que nadie aprende. Se trata de colegios en los que están los niños y niñas, que en teoría son lo más importante. Sin embargo, las prisas por inaugurar centros, los cambios de gobierno, el querer salir en la foto... eso está haciendo mucho daño a las infraestructuras en las que estamos a diario miles de jóvenes y profesionales de la enseñanza. Se dice que la educación es importantísima, pero a la hora de la verdad no se cuida como es debido. Basta ver el estado lamentable de tantas escuelas públicas.

Un director de instituto de Murcia exponía que:

Las carencias o defectos habría que señalarlos precisamente en función de esos sucesivos modelos, pero creo que será adecuado señalar los que son más comunes y especialmente los que persisten a pesar de los nuevos diseños, o en algunos casos como consecuencia de ellos, que es lo más lamentable. Suelen adolecer de falta de espacios comunes amplios y cubiertos para los tiempos de recreo o actividades fuera del aula. Los más antiguos incluso carecen de nada más que la entrada y los pasillos. Es general que las zonas de paso (pasillos) sean estrechas, incluso se han ido estrechando en los más recientes. Las dimensiones de las aulas resultan generalmente insuficientes aunque cumplan la normativa. Esta situación se agrava con los aumentos de ratio que venimos padeciendo. Especialmente inadecuadas son las condiciones acústicas. La acústica es un asunto marginado, y no hace falta pensar sólo en las clases de idiomas, sino que esta profesión se construye sobre la palabra en todas las materias. $Y$ lo mismo sucede con el aislamiento térmico y los cerramientos. Como decía arriba, en los centros más modernos que he visitado sorprende cómo se ha subordinado este tema a la originalidad del diseño, con lucernarios absurdos, paredes acristaladas sin sentido,... A lo que podemos sumar, a pesar de tratarse de una región tan calurosa, una inadecuada ventilación (en algunos de los últimos centros, que se suponían punteros en este tema, ha sido necesario instalar con posterioridad sistemas de calefacción/aire acondicionado para poder impartir clases en ellos).

Un inspector canario afirmaba que:

He advertido y en relación con la pregunta precedente, que en los últimos tiempos ha primado la estética o la belleza exterior, a la funcionalidad de las edificaciones escolares. He visto centros escolares con excesivos "espacios poco funcionales" y con pasillos de dimensiones muy reducidas. Muchas de las aulas, aún cumpliendo lo establecido en la normativa vigente (Real Decreto 132/2010, de 12 de febrero, por el que se establecen los requisitos mínimos de los centros que impartan las enseñanzas del segundo ciclo de la educación infantil, la educación primaria y la educación secundaria), son incómodas y poco adecuadas para favorecer el proceso de enseñanza-aprendizaje. Algunos de los pabellones cubiertos polideportivos, no disponen de la posibilidad de utilizar la luz natural, por lo que es necesario "sobreutilizar" la luz artificial.

Una directora escolar gallega replica que, efectivamente, ha podido constatar carencias y aspectos negativos relevantes:

En Galicia deberían contar con más espacios cubiertos para protegernos de la climatología lluviosa y desde luego es necesario que los centros contaran con salón de actos para los festivales, representaciones, etc. Actualmente los patios cubiertos son en general escasos y las veladas o eventos importantes se deben celebrar en gimnasios pequeños o aulas ordinarias. Otro aspecto negativo que observo en mi centro que data del año 1991 es que tenemos una sala de profesores muy pequeña y las reuniones de claustro se celebran en un aula ordinaria. Por lo tanto habría que estudiar la capacidad del centro escolar para construir salas de profesores adaptadas al número de profesores y permitir la celebración de las reuniones de claustro cómodamente en ese espacio. 
Un responsable político de la Administración balear argumentó que, efectivamente, sí aprecia problemas:

En demasiados casos aparecen problemas de filtraciones de agua de lluvia. También aparecen problemas por el uso de materiales o acabados poco adecuados al uso que se destinan con cientos de alumnos que pasan por los pasillos o que coinciden en el patio.

Otro inspector valenciano afirma que "Hay muchas carencias" y las expone sucintamente:

En primer lugar no se tienen en cuenta los usos educativos habituales solo el Real Decreto. Por ejemplo se construyen salas polivalentes, son necesarias; pero los docentes reclaman aulas para la música, para los idiomas, aula de informática, para atender a los alumnos de PT y AyL, etc. Otro problema es el problema de la calefacción y/o el aire acondicionado que muchas veces no se tiene en cuenta. Las salas para la reprografía o la falta de almacenes para material general o del equipamiento de educación física es otra deficiencia habitual. En otras ocasiones el problema es más elemental y se debe al diseño: mala orientación de los edificios, materiales no adecuados a la zona, etc.

Una arquitecta de Madrid fue contundente al indicar que ha podido constatar "Muchísimas carencias". Asimismo, critica que "Los modelos de centros educativos actuales son exactamente iguales a los centros diseñados a principios del siglo XX en España”, pero rescata algunos casos destacables, al constatar que "Sin embargo hay ejemplos de los años 50, y 60 en España que presentan unos modelos muy interesantes en los que pedagogía y espacio estaban claramente relacionados”.

Una inspectora vasca sostuvo que:

Los espacios que los centros ofrecen son, en muchos casos, auténticos corsés para la vida en los mismos, sobre todo para el profesorado más innovador. Además de la ubicación, la construcción deja mucho que desear. En muchos casos, se da el visto bueno de recepción de obra cuando existen deficiencias, lo que supone que en muy poco tiempo se hayan de realizan obras menores para subsanarlas.

Aunque el centro sea nuevo, como el diseño es cerrado, obliga a hacer obras que permitan adaptarlo, de alguna manera, a las necesidades del centro concreto. Que no se tengan en cuenta las condiciones climatológicas de la zona, sobre todo la luz, la temperatura y los patios: cubiertos cuando sean necesarios o con elementos naturales (árboles y jardines) en lugar de cemento. Aunque existe legislación al respecto, el famoso decreto 1001, los centros más antiguos no responden a ello y hacer cambios es siempre muy difícil y complicado para los centros públicos, sobre todo de primaria.

\subsection{Resultados en relación con la tercera pregunta}

Sobre la última cuestión planteada a los expertos informantes, basada en las mejoras en el diseño y construcción de centros escolares públicos, un inspector realizó una clara propuesta de mejora basada en tres aspectos:

En primer lugar habría que modificar la normativa incorporando espacios educativos especializados: música, idiomas, informática... También habría que dar respuesta al tema del calor y del frio pues las instalaciones son insuficientes; quizá la energía solar podría ser una solución. En segundo lugar para diseñar el edificio debería tenerse en cuenta la realidad del centro educativo (unidades, tipo de docentes que intervienen...) y por supuesto la ubicación del centro, pues por ejemplo hay centros completamente acristalados que son auténticos invernaderos. Por último desearía señalar la situación tan particular en la que se encuentran algunos centros como por ejemplo las escuelas de educación infantil primer ciclo o los centros de formación de personas adultas, cuya normativa es muy laxa y desigual según comunidades autónomas. 
Una inspectora anotó también numerosas propuestas, al exponer que:

Habría que hacer más espacios multifuncionales y con posibilidades de división o ampliación que posibilite usos múltiples y diversos. Deben ocupar los centros vítales de las ciudades. Los niños y niñas deben ser visibles como parte importante de la comunidad. Diseñarlos para cada contexto, adecuándose al mismo y no un modelo único que se replique. El diseño de los centros de infantil, debe exigir especial cuidado, sustituir las escaleras por rampas, luces a la altura del alumnado, puntos de agua en las clases, baños, adaptados, espacios diferentes, etc. La calidad de la construcción ha de ser excelente y se debe controlar de modo riguroso. No sólo por razones de seguridad, sino también de funcionalidad y uso. Hacer de la construcción de un centro escolar, una posibilidad para crear comunidad educativa: participar en el diseño y posterior cuidado del edificio

Otro tema importante es el referido al mobiliario y la necesidad de que se tengan en cuenta las diferencias individuales del alumnado de un mismo grupo de edad (más notable en Secundaria) y que las mesas y sillas, se adapten a las necesidades de cada alumno/a. Se habla mucho de ergonomía pero no se cumple. En esto momentos, en los que hay que repensar el sistema educativo de arriba abajo, las construcciones escolares, los espacios, son un elemento clave, porque, son elementos potenciadores o limitantes y, en todo caso, educar en un sentido u otro No hay más ver los espacios de las empresas más innovadoras y cómo se crean lugares para la interacción, la creatividad y la autonomía.

Una arquitecta de Madrid recalcó que:

un colegio no es un objeto ensimismado en la ciudad, sino que debe dialogar con el entorno, responder a las condiciones climáticas de cada lugar, aprovechar la mejor orientación para que sus espacios dispongan al máximo la luz natural y el soleamiento necesario como medida pasiva y por supuesto ser sostenible con el medioambiente utilizando materiales adecuados y gastando el mínimo de energía. En definitiva, el propio edificio debe educar, ser respetuoso y actuar como mediador entre la casa y la ciudad.

Para ello, propone que "en este momento de efervescencia educativa, la búsqueda del colegio ideal se está manifestando a través de transformaciones espaciales totales o parciales en colegios para crear espacios atractivos que estimulen la creatividad y la experimentación”. También declaró que:

La coherencia entre el sistema pedagógico y el espacio donde se desarrolla es esencial para conseguir una formación integral. Los sistemas pedagógicos integrales exigen entornos cuidados y amables que tienen que estar diseñados de forma "personalizada" para adecuarse a un modo de enseñar.

Asimismo, razonaba que:

Desde la primera década del siglo XXI están apareciendo escuelas con una nueva imagen que cambia por completo el imaginario asociado a los centros educativos, empezamos a ver edificios contemporáneos con espacios singulares, coloridos y luminosos, donde los alumnos se motivan también a través del ambiente que viven cada día.

Esta arquitecta atestiguó que "La variedad de espacios es uno de los aspectos más novedosos de las escuelas del siglo XXI, las aulas dejan de ser un lugar cerrado y modular y comienzan a introducirse distintos tipos de ambientes en los que los alumnos desarrollan capacidades diferentes”, y concluye con una propuesta muy concreta:

Para llegar a consolidar una unión real del binomio arquitectura y pedagogía es necesario la implicación de las administraciones públicas. Creemos que ha llegado la hora de sentar en la misma mesa a arquitectos, urbanistas, pedagogos y comunidades escolares para cambiar la normativa existente y elaborar entre todos las nuevas guías de diseño de los centros escolares del siglo XXI. Además, desde la red pública se 
deben lanzar nuevos pliegos de concursos basados en esa nueva guía de diseño. Se necesita garantizar que la concepción y construcción de centros escolares siempre se realicen anteponiendo la calidad arquitectónica y pedagógica a la económica. Un buen ejemplo es el reciente concurso organizado la Secretaría de Educación del Distrito Capital de Bogotá. $Y$ para los centros ya existentes sería fundamental elaborar un plan de "recreación" de la escuela que permita ir transformando y regenerando sus espacios. La arquitectura dedicada a la infancia y su contexto urbano son asuntos considerados fundamentales para las instituciones educativas de un gran número de países. En EEUU los ayuntamientos de Boston y Filadelfia han optado por la renovación de sus espacios educativos con el objetivo de comenzar un plan integral de regeneración urbana.

En este sentido, la mencionada arquitecta apunta que "Para el cambio de paradigma en la educación a través de la transformación de sus espacios se necesita profundizar sobre algunos conceptos fundamentales que no son nuevos pero que se han perdido en los últimos años". Y lo ultima con una propuesta basada en cinco conceptos, que exponemos en la tabla 4.

Tabla 4. Propuesta de mejora del diseño de los nuevos centros educativos del siglo XXI

\begin{tabular}{|c|c|c|}
\hline CONCEPTO & PREguntas ClaVE & PROPUESTA \\
\hline Identidad & $\begin{array}{l}\text { ¿Cómo cambiar la imagen } \\
\text { carcelaria y la obsoleta } \\
\text { estética infantil de los } \\
\text { centros escolares? } \\
\text { ¿Cómo debe ser la imagen } \\
\text { de un colegio? }\end{array}$ & $\begin{array}{l}\text { Cada centro debe trabajar para ofrecer una imagen } \\
\text { propia y que refleje los valores que pro-mueve con } \\
\text { elementos reconocibles y cercanos y otros que doten de } \\
\text { identidad a cada centro. La personalización solo es } \\
\text { posible involucrando a toda la comunidad educativa en } \\
\text { el proceso de transformación. }\end{array}$ \\
\hline Horizontalidad & $\begin{array}{l}\text { ¿Para quién es un } \\
\text { colegio? }\end{array}$ & $\begin{array}{l}\text { Se debe garantizar en toda su configuración espacial la } \\
\text { accesibilidad, inclusión y participación de toda la } \\
\text { comunidad escolar. En definitiva, hay que proporcionar } \\
\text { una horizontalidad en todos sus espacios de aprendizaje } \\
\text { y que el alumnado se sienta parte activa de su } \\
\text { educación. Para ello hay que diseñar ambientes } \\
\text { permeables y transparentes que potencien su uso de } \\
\text { forma democrática y participativa. }\end{array}$ \\
\hline Heterogeneidad & ¿Cómo debe ser un aula? & $\begin{array}{l}\text { La heterogeneidad es indispensable para una enseñanza } \\
\text { lo más personalizada posible, ya no deberían concebirse } \\
\text { aulas repetitivas y sola-mente unidireccionales } \\
\text { (información que parte del profesor hacia el alumno), es } \\
\text { el momento de la no-aula, todos los espacios pueden } \\
\text { funcionar como aulas. Se requieren espacios } \\
\text { heterogéneos que potencien la diversidad de rincones y } \\
\text { ambientes de aprendizaje. }\end{array}$ \\
\hline Convivencia & $\begin{array}{l}\text { ¿Cómo son los espacios } \\
\text { de socialización y } \\
\text { transición? }\end{array}$ & $\begin{array}{l}\text { Los espacios de transición son aquellos donde se } \\
\text { desarrolla la convivencia de la comunidad escolar. Los } \\
\text { antiguos lugares de paso (pasillos y accesos) se } \\
\text { convierten en lugares de encuentro, de socialización y } \\
\text { de aprendizaje. }\end{array}$ \\
\hline Flexibilidad & $\begin{array}{l}\text { ¿Cómo se organiza un } \\
\text { colegio? }\end{array}$ & $\begin{array}{l}\text { Los espacios que se propongan tienen que ser flexibles, } \\
\text { transformables. La organización debe ayudar a que se } \\
\text { pierda la rigidez en los usos y distribuciones y a que se } \\
\text { fomente la versatilidad de los espacios y su fácil } \\
\text { transformación en función de las necesidades de la } \\
\text { comunidad escolar. }\end{array}$ \\
\hline
\end{tabular}

Fuente: Arquitecta de Madrid, informante del estudio empírico. 
Un director de instituto murciano lamenta que:

no se cuenta con quienes utilizamos a diario las instalaciones para procurar infraestructuras lógicas y eficientes. Son una constante los comentarios de compañeros acerca de las discusiones, a posteriori, con los arquitectos para corregir en lo posible defectos de diseño, lo que no siempre es posible.

Una directora escolar gallega reclama que:

$$
\begin{aligned}
& \text { se pide a los responsables de diseñar y construir nuestros centros escolares públicos } \\
& \text { una mayor funcionalidad para que nuestro alumnado y profesorado se encuentre } \\
& \text { cómodo ya que pasamos en el centro muchas horas y una parte muy importante de } \\
& \text { nuestra vida }
\end{aligned}
$$

y sugiere que "los centros escolares públicos deberían contar con mayor superficie cubierta y un verdadero salón de actos", así como también propone que "La Biblioteca Escolar, un espacio privilegiado dentro del centro debería adaptarse al mundo actual y contar con mayores dimensiones". Sin embargo, su mayor preocupación trata sobre las aulas de los más pequeños ya que, según indica, "lo que considero de primerísima necesidad es que las aulas de Educación Infantil cuenten con baños incorporados (sobre todo en $4^{\circ}$ de Educación Infantil para los niños/as de 3 años)”.

En sintonía con lo anterior, un responsable político de la Administración indica que "Normalmente no se tiene en cuenta la opinión de los futuros usuarios del edificio escolar -equipo directivo, profesorado- que podrían orientar en detalles fruto de su experiencia. Aspectos que posteriormente a la finalización de la obra deben modificarse”.

Un arquitecto anotó que "centraría el esfuerzo actual no en la construcción de nuevos edificios sino en la mejora de los existentes", por lo que "de esta experiencia los nuevos edificios también saldrían beneficiados". Abordó la propuesta al decir que "Partiría de un cambio social, vivimos en un mundo ya hecho. La necesidad de la sociedad no es el crecimiento sin límite de ciudades sino la mejora de la arquitectura ya creada”. Sin embargo, puntualizó que "Esta mejora que puede ser mesurable: Mejora de eficiencia energética, de ratios de alumnos... también puede ser real en el entorno de la enseñanza” a la vez que lanzó una propuesta clara:

Mi propuesta sería el enriquecimiento del programa y de la formalización de aspectos puntuales de los edificios ya construidos mediante la intervención de los usuarios. No solo habría que centrarse en el aspecto escolar sino del tejido social o como el edificio escolar puede dar el mayor servicio. Siempre hablamos del diseño para niños, pero la final es el adulto quien decide.

Finalmente, este arquitecto concluyó al recordarnos que:

Un arquitecto trabaja con un programa que se elabora en despachos. La mejora de este programa mediante el trabajo de campo traducido en la interacción entre arquitecto, profesorado, padres, alumnos... permitiría optimizar o pulir soluciones que hoy se repiten por considerarse satisfactoria.

Un inspector propuso como mejora:

la flexibilidad y la versatilidad de los espacios, de modo que puedan utilizarse, eficazmente, como recursos didácticos para procesos de enseñanza y aprendizaje de diversa naturaleza y con distintos tipos de agrupamientos del alumnado. Asimismo, la facilitad técnica para el uso menos "invasivo" y más accesible y normalizado de recursos tecnológicos en tales procesos. 
Otro inspector sugiere cinco aspectos mejorables:

a. Que los centros escolares dispongan de pasillos amplios y que la circulación de alumnos/as sea fluida y evite excesivos contactos.

b. Que no existan demasiadas escaleras y que se utilice pavimento antideslizante.

c. Que las aulas sean amplias y funcionales y que permitan diferentes tipos de agrupamiento del alumnado.

d. Que no existan demasiados cristales en los pasillos y que existan también jardines y espacios de esparcimientos diversos.

e. Que en el diseño de los polideportivos cubiertos se le "consulte" al docente de Educación Física aspectos que pueden ser relevantes para facilitar la optimización del espacio y de la funcionalidad de la misma.

De este modo, tras la exposición de los resultados obtenidos, procedemos a esgrimir las conclusiones que hemos podido alcanzar tras el análisis de los datos.

\section{Discusión y conclusiones}

La preocupación por la arquitectura escolar está siendo un tema candente en la actualidad. Los expertos consultados en esta investigación han aportado ideas y claves suficientes para que podamos alcanzar diversas conclusiones en relación con las tres preguntas que han guiado el estudio empírico.

a) En primer lugar, en relación con la idea de un modelo o patrón definido en el diseño y construcción de los centros escolares públicos, podemos concluir que a pesar de que se ha constatado que hubo un patrón claro en la edificación de centros a partir de la Ley General de Educación de 1970, en la actualidad los centros deben ajustarse a los mínimos establecidos en una normativa estatal (Real Decreto132/2010, de 12 de febrero, por el que se establecen los requisitos mínimos de los centros que impartan las enseñanzas del segundo ciclo de la educación infantil, la educación primaria y la educación secundaria, publicada en el Boletín Oficial del Estado de 12 de marzo de 2010). Sin embargo, esta norma y otras de menor rango que se establecen a nivel autonómico, son solamente el marco sobre el cual se deben ajustar diversos mínimos: tamaño de aulas, de espacios comunes, patios, bibliotecas, etc. que, insistimos, son estipulaciones mínimas que se deben cubrir por ley. A partir de ahí, el diseño de los arquitectos deberá ajustarse también al presupuesto económico de la Administración convocante del concurso. Luego, podemos concluir que, a día de hoy, no hay un modelo o patrón definido que guíe la construcción de escuela, sino únicamente unos requisitos mínimos legales de espacio y un gasto máximo económico presupuestado por la Administración contratante parecen ser los dos ejes que no debe propasar el arquitecto en su diseño, por lo que en ese espacio entre mínimos legales y máximos económicos no quebrantables por el arquitecto, éste puede plasmar diseños adaptados a la nueva realidad del siglo XXI, con amplio margen de mejora en el diseño y construcción escolares, a tenor de las nuevas necesidades sociales y educativas de nuestro tiempo.

b) En segundo lugar, en relación con las carencias o aspectos negativos detectados en el diseño y construcción de los centros escolares públicos, podemos concluir que a pesar de que la casuística de numerosos centros ha mostrado un sinfín de carencias y equivocaciones de los que se debería tomar nota, todavía se siguen cometiendo errores crasos tanto en el diseño como el uso de materiales. En este sentido, concluimos que la 
voz de los expertos participantes en el estudio ha sido clara y notoria, por lo que se deberían ajustar los centros a unas particularidades del enclave en el que se erigirán y de los usuarios que le van a dar uso (climatología, ubicación, usos didácticos actuales, necesidades infantiles, etc.), en orden a que las infraestructuras educativas se adapten a las nuevas necesidades de los alumnos y profesorado, y no sean éstos los que deban amoldarse a golpe de cincel a diseños en serie de escuelas e institutos una vez ya construidos con notables imperfecciones.

c) Finalmente, en relación con las propuestas de mejora en el diseño y construcción de centros escolares públicos, podemos concluir que la Administración educativa no puede volver a apostar, de ningún modo, por centros educativos prêt-à-porter, diseñados en serie bajo unas demandas generalizadas para abaratar los costes, sino que debe dirigir su acción política para que permita, favorezca y logre espacios arquitectónicos escolares de alta costura, únicos, especiales, flexibles, realizados con las mejores intenciones políticas, diseñados con las más altas ideas arquitectónicas y con materiales superiores. Sólo así volveremos a ese espíritu pedagógico institucionista renovador de la sociedad de la ILE que tanto bien hizo a la escuela y a los ciudadanos, pero ahora con el conocimiento de los aspectos positivos y aquéllos que no lo son tanto sobre el diseño y construcción de nuestros centros educativos públicos. Las percepciones, pautas y propuestas de mejora ofrecidas por los expertos informantes en esta investigación han sido claras.

A partir de datos de este estudio, proponemos la creación de una junta permanente o comité de expertos que asesore a la Administración educativa (autonómica y estatal) en materia de arquitectura escolar, formado -no exclusivamente pero sí necesariamentepor directores escolares, directores de instituto, inspectores de educación y arquitectos especialistas en centros educativos. Pensamos que con una acción asesora y supervisora sobre los parámetros de los centros de próxima creación a establecer por la Administración educativa sería de naturaleza muy beneficiosa para éstos, y por ende, para la Administración y sus administrados.

En consecuencia y definitivamente, aún sin ese comité de expertos asesores (ojalá se materialice pronto), estamos convencidos de que con el talento y saber propedéutico madurado, global y técnico de los arquitectos, junto con los avances en materia tecnológica y de elementos arquitectónicos, unido a una amplitud de miras de los responsables políticos y con una adecuada simbiosis con los profesionales de la educación previa a la edificación de los centros escolares, podemos afirmar que los artífices del nuestra arquitectura escolar tienen los mejores elementos a su disposición para que los mejores centros sean de verdad lo que en palabras de un director informante deben ser "infraestructuras lógicas y eficientes", que gocen además de la necesaria "flexibilidad" (concepto avalado y requerido por el conocimiento académico y técnico, así como por informantes de este estudio). Estas son las escuelas de la sociedad del conocimiento del siglo XXI que tanto anhelamos y necesitamos. La empresa bien lo vale, se trata de nuestros hijos e hijas: nuestro mayor tesoro.

\section{Referencias}

Bello, L. (1926). Viaje por las escuelas de España. Madrid: Magisterio Español.

Bello, L. (2007). Viaje por las escuelas de Andalucía. Sevilla: Renacimiento. 
Cabanellas, I. y Eslava, C. (Coords.). (2005). Territorios de la infancia. Diálogos entre arquitectura y pedagogía. Barcelona: Graó.

Cabarrús, F. (1973). Cartas sobre los obstáculos que la naturaleza, la opinión y las leyes oponen a la felicidad pública. Madrid: Castellote.

Carrió, P. J., Domènech, M. V. y Ramis, A. (2015). Les escoles de les Illes Balears en temps de la II República. Palma: Talaiots.

Coleman, J. S. (1985). Schools and the communities they serve. Phi Delta Kappan, 66(8), 527-532.

Curtis, E. (2003). School builders. Chihester: Wiley-Academy, John Miley \& Sons.

Delors, J. (1996). La educación encierra un tesoro. Informe a la UNESCO de la Comisión Internacional sobre la Educación para el siglo XXI, presidida por Jacques Delors. México: UNESCO.

Faure, E. (1972). Apprendre à étre [Aprender a ser]. París: UNESCO.

Giner de los Ríos, F. (1884a). Campos escolares. Madrid: Biblioteca Pedagógica de la Institución Libre de Enseñanza.

Giner de los Ríos, F. (1884b). El edificio de la escuela. Madrid: Biblioteca Pedagógica de la Institución Libre de Enseñanza.

Gómez Dacal, G. (1992). Centros educativos eficientes. Barcelona: PPU.

Gómez Dacal, G. (1996). Curso de organización escolar y general. Madrid: Escuela Española.

Hoyuelos, A. (2004). La ética en el pensamiento y obra pedagógica de Loris Malaguzzi. Barcelona: Octaedro.

Kamin, B. (2002). Designed bank tower, more than 200 schools. Chicago Tribune. Recuperado de http://articles.chicagotribune.com/2002-05-29/news/0205290303_1_architects-schoolboard-mr-brubaker

Jovellanos, G. M. M. (1956). Memoria pública. Obras. Tomo XLVI. Madrid: Biblioteca de Autores Españoles.

Kliment, S. A. (2001). Preface. En S. A. Kliment (Ed.), Elementary and secondary schools (pp. xi-xiii). Nueva York, NY: Bradford Perkins-John Miley \& Sons.

Lincoln, Y. y Guba, E. (1985). Naturalistic inquiry. Los Angeles, CA: Sage Publications.

Luzuriaga, L. (1931). Bases para un anteproyecto de ley de instrucción pública inspiradas en la idea de la escuela única. Revista de Pedagogía, 9, 117, 417-420.

Maykut, P. y Morehouse, R. (1999). Investigación cualitativa. Una guía práctica y filosófica. Barcelona: Hurtado.

MEC. (1989). Libro blanco para la reforma del sistema educativo. Madrid: Autor.

MECD. (2016). Panorama de la educación. Indicadores de la OCDE 2016. Informe español. Madrid: Instituto Nacional de Evaluación Educativa.

OCDE. (2016). Trends shaping education 2016. París: OCDE.

Puelles Benítez, M. (2004). Elementos de política de la educación. Madrid: UNED.

Puelles Benítez, M. (2008). Política y educación en la España contemporánea. Madrid: UNED.

Repullés y Vargas, E. M. (1878). Disposición, construcción y mueblaje de las escuelas públicas de instrucción primaria. Madrid: Fortanet.

Sarramona, J. (2002). La aventura de innovar. El cambio en la escuela. Madrid: Morata. 
Serrano de Haro, A. (1973). La inspección, Alejandro Casona y otros recuerdos. Escuela Española, 2029, $777-791$.

Sureda García, B. (2015). Pròleg. Les fotografíes escolars. En P. Carrió, M. Domènech y A. Ramis (Eds.), Les escoles de les Illes Balears en temps de la II República (pp. 17-18). Palma: Talaiots.

Torrres Balbás, L. (1933). Los edificios escolares vistos desde la España rural. Recuperado de https://sede.educacion.gob.es/publiventa/d/21574/19/o

Viñao, A. (1990). Innovación pedagógica y racionalidad científica. La escuela graduada pública en España (1898-1936). Madrid: Akal.

Viñao, A. (2002). Sistemas educativos, culturas escolares y reformas. Madrid: Morata.

Viñao, A. (2006). Templos de patria, templos del saber. Los espacios de la escuela y la arquitectura escolar. En A. Escolano Benito (Dir.), Historia ilustrada de la escuela en España. Dos siglos de perspectiva histórica (pp. 47-71). Madrid: Fundación Germán Sánchez Ruipérez.

\section{Breve CV del autor}

\section{Alexandre Camacho Prats}

Doctor en Pedagogía (Premio Extraordinario de Doctorado) por la Universitat de Barcelona, Máster universitario en Dirección y Gestión de Centros Educativos por la Universidad de Deusto, licenciado en Pedagogía por la UNED y maestro por la Universitat de les Illes Balears. Ha ejercido en diversas etapas desde la Educación Infantil hasta la Universidad. Ha sido director escolar y es el autor de la primera tesis doctoral sobre la Inspección educativa balear. Su ámbito de investigación se centra en la supervisión educativa y la organización escolar. Ponente invitado y conferenciante en congresos nacionales e internacionales, miembro de comités científicos de congresos y revistas científicas, es funcionario de carrera del Cuerpo de Maestros en Palma de Mallorca y profesor en la Universitat de Barcelona. ORCID ID: 0000-0002-7718-8617. Email: alexcprats@hotmail.com 